\title{
Current antiarrhythmic therapy for nonvalvular atrial fibrillation in Spain. Data from the FANTASIIA registry
}

\author{
Tratamiento antiarrítmico actual de la fibrilación auricular no valvular en \\ España. Datos del Registro FANTASIIA
}

Inmaculada Roldán Rabadána, Manuel Anguita Sánchez, Francisco Marín, María Angustias Quesada, José Camacho Siles, Rafael Peinado, Vicente Bertomeu, Ángel Cequier Fillat, Lina Badimón, Javier Muñiz, on behalf of the FANTASIIA study researchers

\begin{abstract}
Introduction and objectives. Recently, there have been many developments in the management of nonvalvular atrial fibrillation, antiarrhythmic and anticoagulant therapy, and nonpharmacological treatment, but these developments are not applied immediately in clinical practice. The aim of this study was to identify the overall management and antiarrhythmic therapy used in the current general population of patients with nonvalvular atrial fibrillation in Spain. Methods. A prospective, observational study of 1318 consecutive anticoagulated patients with nonvalvular atrial fibrillation, recruited between June 2013 and March 2014. We analyzed the patients' general characteristics, management, and antiarrhythmic therapy.

Results. Mean age was $73.8 \pm 9.4$ years; $42.5 \%$ were women. Atrial fibrillation was paroxysmal in $28 \%$ of the patients, permanent in 50\%, persistent in $17.6 \%$, long-standing persistent in $4.5 \%$, and new-onset in 66 patients $(5 \%)$. A rhythm control strategy was chosen in $39.4 \%$ of the patients and rate control in $60.6 \%$. Beta-blockers were prescribed in $60.2 \%$ of the patients, digoxin in $19.5 \%$, and calcium channel antagonists in $10.7 \%$. The antiarrhythmic agents used were amiodarone (12.6\%), flecainide $(8.9 \%)$, propafenone $(0.4 \%)$, sotalol $(0.5 \%)$, and dronedarone (2.3\%). Cardioversion had been performed previously in $41.9 \%$ of the patients, ablation in $3.4 \%$, and atrial appendage closure in $0.2 \%$.

Conclusions. Currently, patients with nonvalvular atrial fibrillation in Spain are managed mainly with rate control, and beta-blockers in particular. They receive few antiarrhythmic agents and only a very small number of these patients undergo nonpharmacological treatments.
\end{abstract}

\section{Resumen}

Introducción y objetivos. Recientemente se han producido numerosas novedades en el manejo de la fibrilación auricular no valvular y el tratamiento antiarrítmico, anticoagulante y no farmacológico empleado, pero su aplicación a la clínica no es inmediata. El objetivo del trabajo es conocer las características generales de manejo y tratamiento antiarrítmico de una población general de pacientes con fibrilación auricular no valvular actualmente en España.

Métodos. Estudio observacional y prospectivo de 1.318 pacientes consecutivos con fibrilación auricular no valvular, anticoagulados y reclutados entre junio de 2013 y marzo de 2014. Se analizan sus características generales, el manejo y el tratamiento antiarrítmico utilizado.

Resultados. La media de edad era 73,8 \pm 9,4 años; eran mujeres el 42,5\%. La fibrilación auricular fue paroxística en el $28 \%$ de los casos, permanente en el $50 \%$, persistente en el $17,6 \%$, persistente de larga duración en el $4,5 \%$ y de novo en 66 pacientes (5\%). Se eligió control del ritmo en el 39,4\% de los casos y de frecuencia en el 60,6\%. Tomaron bloqueadores beta el $60,2 \%$, digoxina el $19,5 \%$ y antagonistas del calcio el 10,7\%. Los antiarrítmicos empleados fueron amiodarona $(12,6 \%)$, flecainida $(8,9 \%)$, propafenona $(0,4 \%)$, sotalol $(0,5 \%)$ y dronedarona $(2,3 \%)$. Se realizó cardioversión previa en el $41,9 \%$, ablación en el 3,4\% y cierre de orejuela en el $0,2 \%$.

Conclusiones. Actualmente en nuestro país se maneja a los pacientes con fibrilación auricular no valvular preferentemente con control de frecuencia, sobre todo con bloqueadores beta, reciben pocos antiarrítmicos y se los somete en muy baja proporción a tratamientos no farmacológicos.

Keywords. Nonvalvular atrial fibrillation; Antiarrhythmic therapy; Cardioversion; Ablation; FANTASIIA registry

Palabras clave: Fibrilación auricular no valvular; Tratamiento antiarrítmico; Cardioversión; Ablación; Registro FANTASIIA 
Abbreviations: AF, atrial fibrillation; HF, heart failure; NVAF, nonvalvular atrial fibrillation; OAC, oral anticoagulant

\section{Introduction}

Atrial fibrillation (AF) is the most common arrhythmia in Western countries. Prevalence, estimated at $1.5 \%$ to $2 \%,{ }^{1}$ increases with age, ranging from $1 \%$ in individuals younger than 60 years to $12 \%$ in the group aged 75 to 84 years. More than a third of patients with AF are aged 80 years or older. ${ }^{1 \text { and } 2}$ Recently, the Spanish OFRECE study estimated that AF prevalence in Spain was $4.4 \%$ in adults older than 40 years and $17.7 \%$ in those aged 80 or older. ${ }^{3}$ This arrhythmia is often associated with structural heart disease and other chronic conditions. It leads to significant morbidity and mortality (increased mortality and stroke risk, heart failure $[\mathrm{HF}]$, dementia, etc), and increased hospital admissions and economic burden. . $^{2,5,6,7,8,9 \text { and } 10}$

Since 2010, European and US guidelines on AF have been published almost yearly, reflecting the major changes in the management of patients with this condition. This whirlwind of changes is the result of the successive introduction of more discriminative embolism and bleeding risk indices, the key role of implantable cardiac devices in silent AF, novel oral anticoagulants (OAC) and new antiarrhythmic agents, and the development of ablation. Recently, nonvalvular atrial fibrillation (NVAF) has been defined as AF in the absence of rheumatic mitral stenosis, heart valve prosthesis, or mitral valve repair. ${ }^{1}$ Clinical practice guidelines show general consensus in their recommendations, which reflect these major changes in overall management, and pharmacological and nonpharmacological decisions (such as whether to follow a rhythm or rate control strategy in initial NVAF management, and indications for classic and new antiarrhythmic agents). ${ }^{11}$ However, these guidelines are not immediately applied in routine clinical practice, despite their strong clinical trial-based evidence and high class of recommendation.

The aim of this study was to analyze the current management of NVAF, choice of rhythm or rate control strategies, and the use of antiarrhythmic therapy and nonpharmacological treatment in a general, unselected population of patients with NVAF in Spain.

\section{Methods}

\section{Study Data and Design}

The data for this study were taken from the FANTASIIA Registry (Spanish acronym for Atrial fibrillation: Influence of anticoagulation level and type on stroke and bleeding event incidence), a prospective, observational, national, multicenter study that is collecting general information on the current situation and characteristics of the Spanish population with any type of NVAF, following the European $\mathrm{AF}$ guideline criteria. ${ }^{1}$ The main aim of the registry is to evaluate the incidence of thromboembolic and bleeding events in an unselected population of patients with NVAF over 3 years, specifically with reference to the use and type of antithrombotic agent, vitamin $\mathrm{K}$ antagonist (VKA) and direct OAC, as well as anticoagulation adjustment (in patients receiving VKA). The FANTASIIA Registry is designed as an initial enrolment visit and 3 follow-up visits at 1, 2, and 3 years. The patients' clinical and laboratory data are being collected in an electronic case report form.

In our study, we analyzed a cross-sectional baseline data set from the FANTASIIA enrolment visit, focusing on the secondary endpoints of the registry, which concern the general characteristics of NVAF management, initial AF control strategy, rhythm or rate control, treatment type, antiarrhythmic class, and nonpharmacological treatment.

\section{Study Population}

In this preliminary analysis, we studied 1318 consecutive patients, seen at 50 outpatient clinics, with a diagnosis of NVAF (excluding patients with rheumatic mitral valve disease or valvular prostheses), entered in the FANTASIIA Registry by 81 investigators $(81 \%$ cardiologists, $11 \%$ primary care physicians, and 8\% internists) between June 2013 and March 2014. The clinics were randomly selected, and located throughout Spain. Inclusion criteria were patients older than 18 years who had been receiving anticoagulant therapy ( $80 \%$ VKA and $20 \%$ direct OAC, ie, dabigatran, rivaroxaban or apixaban) for at least 6 months before enrolment. The patients were managed according to routine clinical practice. The FANTASIIA Registry complies with all the principles of the Declaration of Helsinki and the study 
protocol was approved by the Clinical Research Ethics Committee at Hospital Universitario de Alicante and by all the local ethics committees. All study participants signed the informed consent.

\section{Statistical Analysis}

Quantitative variables were described using the mean \pm standard deviation or median [interquartile range], depending on whether they followed a normal distribution, which we tested with the KolmogorovSmirnov method. For between-group comparisons, we used the Student $t$ test for continuous variables and the chi-square test for qualitative variables. Statistical significance was defined as $P<.05$. Statistical analyses were performed with SPSS statistical package version 12 .

\section{Results}

\section{Baseline Characteristics of Study Patients}

We enrolled 1318 patients throughout Spain who met the aforementioned inclusion and exclusion criteria between June 2013 and March 2014. Baseline characteristics are shown in Table 1. Mean age was 73.8 years ( \pm 9.4 years) and 758 patients $(57.5 \%)$ were men. The most prevalent risk factor was hypertension, which was observed in 1068 patients $(81.0 \%)$, followed by hypercholesterolemia in $711(54.0 \%)$, and diabetes mellitus in $386(29.0 \%)$. Other notable comorbidities were ischemic stroke, in 210 patients (15.9\%), and major bleeding, in $44(3.3 \%)$. At the initiation visit, most patients, $\mathrm{n}=948(71.9 \%)$, were treated with acenocoumarol, 68 (5.2\%) with warfarin, and $303(23.0 \%)$ with a novel direct OAC. Left atrial appendage closure had been performed in 3 patients $(0.2 \%)$. Mean scores for thromboembolic and bleeding risk indices were: $\mathrm{CHADS}_{2}, 2.32 ; \mathrm{CHA}_{2} \mathrm{DS}_{2}-\mathrm{VASc}, 3.79$, and HAS-BLED, 1.99. $\mathrm{CHA}_{2} \mathrm{DS}_{2}-$ $\mathrm{VASc}=0$ was found in $4.9 \%$ of the patients; $\mathrm{CHA}_{2} \mathrm{DS}_{2}-\mathrm{VASc}=1$ in $24.1 \%$, and $\mathrm{CHA}_{2} \mathrm{DS}_{2}-\mathrm{VASc} \geq 2$ in $71 \%$ of the patients. HAS-BLED score was $<3$ and $\geq 3$ in $72.4 \%$ and $27.6 \%$ of the patients, respectively. Antiplatelets were used in 126 patients $(9.8 \%)$, aspirin in 95 (7.4\%), clopidogrel in $21(1.6 \%)$, prasugrel in $1(0.1 \%)$, and dual antiplatelet therapy was used in 9 patients $(0.8 \%)$. 
Table 1. Baseline Characteristics of the Study Population

\begin{tabular}{|c|c|}
\hline Patients & 1318 \\
\hline Women & $560(42.5)$ \\
\hline Age, years & $73.8 \pm 9.4$ \\
\hline Age $\geq 75$ years & $689(52.3)$ \\
\hline \multicolumn{2}{|l|}{ Cardiovascular risk factors } \\
\hline Hypertension & $1068(81.0)$ \\
\hline Hypercholesterolemia & $711(54.0)$ \\
\hline Diabetes mellitus & $386(29.3)$ \\
\hline Smoker & $60(4.6)$ \\
\hline \multicolumn{2}{|l|}{ Concomitant disease } \\
\hline Renal disorder & $251(19.0)$ \\
\hline Hepatic impairment & $13(1.0)$ \\
\hline COPD and/or sleep apnea & $222(16.8)$ \\
\hline Peripheral vascular disease & $92(7.0)$ \\
\hline Previous stroke & $210(15.9)$ \\
\hline Thyroid dysfunction & $173(13.1)$ \\
\hline Alcohol or drug use & $210(15.9)$ \\
\hline Major bleeding & $44(3.3)$ \\
\hline Previous heart disease & $629(47.7)$ \\
\hline Heart failure & $376(28.5)$ \\
\hline Coronary artery disease & $245(18.6)$ \\
\hline \multicolumn{2}{|l|}{ CHADS2 } \\
\hline 0 & $64(4.9)$ \\
\hline 1 & $318(24.1)$ \\
\hline$\geq 2$ & $936(71.0)$ \\
\hline \multicolumn{2}{|l|}{ CHA2DS2-VASc } \\
\hline 0 & $16(1.2)$ \\
\hline 1 & $86(6.5)$ \\
\hline$\geq 2$ & $1216(92.3)$ \\
\hline HAS-BLED $\geq 3$ & $363(27.7)$ \\
\hline \multicolumn{2}{|l|}{ Concomitant treatment } \\
\hline Diuretics & $784(59.5)$ \\
\hline ACE inhibitor & $411(31.2)$ \\
\hline ARB & $540(41.0)$ \\
\hline Statins & $742(56.3)$ \\
\hline Antiplatelets & $130(9.9)$ \\
\hline \multicolumn{2}{|l|}{ Anticoagulation therapy } \\
\hline Vitamin $\mathrm{K}$ antagonists & $1016(77.1)$ \\
\hline Acenocoumarol & 948 (71.9) \\
\hline Warfarin & $68(5.2)$ \\
\hline Novel direct anticoagulants & $303(23.0)$ \\
\hline
\end{tabular}

$\mathrm{ACE}$, angiotensin-converting enzyme; $\mathrm{ARB}$, angiotensin receptor blockers; $\mathrm{CHADS}_{2}$ : heart failure, hypertension, age $\geq 75$ years, diabetes mellitus, ictus/transient ischemic attack; COPD, chronic obstructive pulmonary disease; HAS-BLED: hypertension, abnormal renal/liver function, stroke, recent bleeding history or predisposition, labile international normalized ratio, elderly, use of drugs predisposing to bleeding/alcohol abuse; VASc: vascular disease, age 65 to 74 years, female sex.

Data are expressed as no. $(\%)$ or mean \pm standard deviation.

\section{Type of Atrial Fibrillation and Type of Control Strategy Chosen}

Atrial fibrillation was paroxysmal in 367 patients (28\%), permanent in $656(50 \%)$, persistent in 231 (17.6\%) and long-standing persistent in 59 (4.5\%). New-onset AF was found in 66 patients (5\%). Time since AF diagnosis was 3.2 years (1.8 years). Nearly a third of the patients $(32.2 \%)$ were in sinus rhythm at the baseline visit. A rhythm control strategy was chosen in $39.4 \%$ of the patients $(45.3 \%$ of the patients younger than 75 years and $30.2 \%$ aged 75 years or older). A rate control strategy was chosen in $60.6 \%$ (54.7\% younger than 75 years and $69.8 \%$ aged 75 years or older) $(P<.001)$. Cardioversion had been performed previously in $41.9 \%$ (electrical cardioversion in $19 \%$, pharmacological cardioversion in $22.9 \%)$. Ablation had been performed previously in $3.4 \%$ (2.2\% for paroxysmal AF, $1.3 \%$ for persistent $\mathrm{AF}$, and $0.15 \%$ for long-standing persistent AF). Table 2 shows the characteristics of patients classified by rhythm or rate control strategy. Patients who received rhythm control were younger, had a lower prevalence of diabetes mellitus, chronic obstructive pulmonary disease, renal impairment and HF, and a higher prevalence of thyroid dysfunction history. The modified Charlson comorbidity index was lower in this group. Rhythm control was chosen in $44.1 \%$ of the patients seen by cardiologists and in $19.2 \%$ seen by internists or primary care physicians $(P<.001)$. There were no significant differences for the other variables analyzed ( Table 2). 
Table 2. Characteristics of Patients Classified by Rhythm or Rate Control Strategy

\begin{tabular}{|c|c|c|c|}
\hline & Rhythm control & Rate control & $P$ \\
\hline Patients $(\mathrm{n}=1318)$ & 39.4 & 60.6 & \\
\hline Age, years & $71.0 \pm 9.3$ & $75.5 \pm 9.0$ & $<.001$ \\
\hline Women & 44.5 & 41.2 & .240 \\
\hline \multicolumn{4}{|l|}{ Comorbidities and CVRF } \\
\hline History of hypertension & 80.5 & 81.7 & .589 \\
\hline History of hyperlipidemia & 55.5 & 53.0 & .375 \\
\hline Diabetes mellitus & 25.3 & 31.9 & .011 \\
\hline Current smoker & 5.22 & 4.1 & .361 \\
\hline COPD/OSA & 12.9 & 19.5 & .002 \\
\hline Kidney disease & 16.0 & 20.9 & .026 \\
\hline Dialysis & 0.2 & 0.9 & .119 \\
\hline Liver disorder & 0.9 & 1.0 & .946 \\
\hline Cancer & 7.2 & 9.1 & .198 \\
\hline Aortic or lower limb arterial disease & 6.0 & 7.5 & .283 \\
\hline Previous stroke & 16.1 & 18.8 & .196 \\
\hline Previous noncerebral embolism & 2.1 & 2.6 & .558 \\
\hline Thyroid dysfunction & 16.6 & 10.8 & .002 \\
\hline $\begin{array}{l}\text { Use of drugs predisposing to bleeding or alcohol } \\
\text { abuse }\end{array}$ & 2.9 & 4.6 & .113 \\
\hline Modified Charlson comorbidity index & $0.98 \pm 1.11$ & $1.27 \pm 1.20$ & $<.001$ \\
\hline \multicolumn{4}{|l|}{ Heart history } \\
\hline Previous heart disease & 45.2 & 49.5 & .133 \\
\hline Heart failure & 24.7 & 33.1 & .001 \\
\hline Previous coronary disease & 19.3 & 18.2 & .609 \\
\hline Previous acute coronary syndrome & 15.4 & 14.1 & .482 \\
\hline Previous coronary revascularization & 10.8 & 11.1 & .899 \\
\hline Dilated cardiomyopathy & 11.8 & 12.5 & .680 \\
\hline Hypertrophic cardiomyopathy & 2.7 & 2.7 & .952 \\
\hline Chronic pericardial disease & 0.2 & 0.4 & .556 \\
\hline Aortic valve disease & 2.1 & 2.9 & .396 \\
\hline HT-induced left ventricular hypertrophy & 15.4 & 16.7 & .553 \\
\hline Previous bradyarrhythmia & 6.3 & 6.6 & .844 \\
\hline Previous ablation & 3.8 & 2.4 & .122 \\
\hline Pacemaker & 6.0 & 7.7 & .248 \\
\hline
\end{tabular}

COPD, chronic obstructive pulmonary disease; CVRF, cardiovascular risk factors; HT, hypertension; OSA, obstructive sleep apnea. Data are expressed as a percentage or mean \pm standard deviation.

\section{Antiarrhythmic and Rate Control Agents Used}

Antiarrhythmic agents were only used in $24.7 \%$ of patients. The drugs most frequently used for heart rhythm control were amiodarone $(12.6 \%)$, flecainide $(8.9 \%)$, propafenone $(0.4 \%)$, sotalol $(0.5 \%)$, and dronedarone $(2.3 \%)$. The drugs most commonly used for heart rate control were beta-blockers $(60.2 \%)$, digoxin (19.5\%), and calcium channel antagonists (verapamil or diltiazem) (10.7\%). Table 3 shows the number of patients receiving each drug alone and in combination, in the whole group and by rhythm and rate subgroups. No patients received a combination of 2 or more Class I or III antiarrhythmic agents, while $13.9 \%$ received a combination of 2 or more rate-slowing drugs $(6.5 \%)$ or an antiarrhythmic plus a rate-slowing drug (7.4\%). The most common combinations were an antiarrhythmic plus beta-blocker, and beta-blocker plus digoxin (Table 3). Antiarrhythmic agents were more common in the rhythm control group $(55.9 \%$ vs just $4.5 \%$ in the rate control group; $P<.001$ ), and rate-slowing drugs were more common in the rate control group $(92.4 \%$ vs $68.5 \%$ in the rhythm control group; $P<.001)$. The combination of antiarrhythmic and rate-slowing drugs was more common in the rhythm control group ( $15.4 \%$ vs $0.7 \%$ in the rate control group, $P<.001$ ), and the combination of different rate-slowing drugs was more common in the rate control group $(10.4 \%$ vs $2.9 \%$ in the rhythm control group; $P<.001)($ Table 3). 
Table 3. Antiarrhythmic and Rate-slowing Drugs, Alone and in Combination, in the Total Group and by Rhythm and Rate Control Subgroups

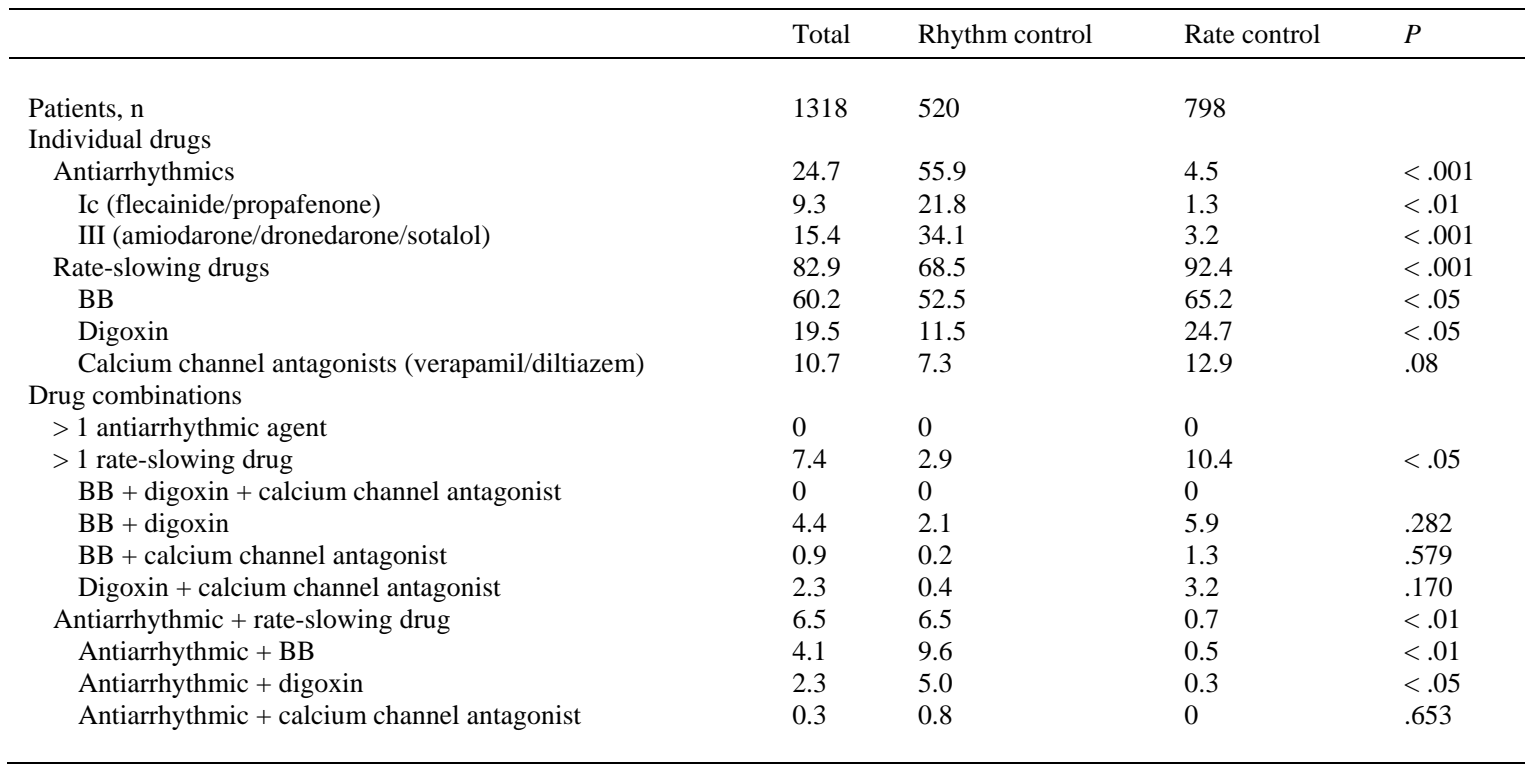

BB, beta-blockers.

Data are expressed as a percentage unless otherwise indicated.

We also observed differences in the type of drugs used according to left ventricular ejection fraction (LVEF) function. The LVEF was $<45 \%$ in 206 patients ( $15.6 \%$ of the total) and $\geq 45 \%$ in the remaining 1112 patients $(84.4 \%)$. The rhythm control strategy was less common among patients with reduced LVEF (29.1\% vs $41.4 \% ; P<.001)$. The rate control strategy was more common in both groups, with a marked difference in the reduced LVEF group (70.9\% vs $58.6 \% ; P<.001)$. Table 4 shows the distribution of antiarrhythmic agents by LVEF function. Among patients with reduced LVEF, the use of class III antiarrhythmics was more common than class Ic antiarrhythmics (15.5\% vs $0.5 \%)$. Beta-blockers were the most commonly used rate-slowing drug in both groups. Digoxin was the most frequently used drug in patients with reduced LVEF function.

Table 4. Management and Antiarrhythmic Agents Used, Classified by Reduced $(<45 \%)$ or Preserved $(\geq 45 \%)$ Left Ventricular Ejection Fraction

\begin{tabular}{lllll}
\hline & Total & LVEF $<45 \%$ & LVEF $\geq 45 \%$ & $P$ \\
\hline Patients, $n$ & 1318 & 206 & 1112 & \\
Control strategy & & & & \\
$\quad$ Rhythm control & 39.4 & 29.1 & 41.4 & $<.001$ \\
$\quad$ Rate control & 60.6 & 70.9 & 58.6 & $<.001$ \\
Antiarrhythmics & 24.7 & 16.0 & 26.2 & $<.01$ \\
$\quad$ Ic (flecainide/propafenone) & 9.3 & 0.5 & 10.9 & .065 \\
$\quad$ III (amiodarone/dronedarone/sotalol) & 15.4 & 15.5 & 15.3 & $<.01$ \\
Rate-slowing drugs & 82.9 & 67.9 & 85.7 & $<.05$ \\
$\quad$ Beta-blockers & 60.2 & 50.5 & 61.9 & $<.05$ \\
$\quad$ Digoxin & 19.5 & 26.2 & 18.2 & $<.05$ \\
$\quad$ Calcium channel antagonists (verapamil/diltiazem) & 10.7 & 2.9 & 12.1 & \\
\hline
\end{tabular}

LVEF, left ventricular ejection fraction.

Data are expressed as a percentage unless otherwise indicated. 


\section{Differences Between Patients Seen by Cardiologists or Noncardiologists}

Table 5 shows the characteristics and management of patients seen by cardiologists (1066 patients [80.8\%]) and internists or primary care physicians (252 [19.2\%]). There were no relevant between-group differences in most patient characteristics, except for older age, a higher prevalence of diabetes mellitus and renal impairment, and a slightly higher modified Charlson comorbidity index in patients seen by cardiologists. The prevalence of other cardiovascular risk factors, comorbidities and associated heart diseases (including coronary disease and HF) was similar in both groups (Table 5). As mentioned earlier, rhythm control strategy was significantly less common among patients seen by internists or primary care physicians. Cardiologists used more antiarrhythmic agents (class Ic and III alike), while internists and primary care physicians used more rate control drugs (Table 5). We observed differences in the type of rate-slower drug used: cardiologists used beta-blockers much more, and internists and primary care physicians used digoxin more.

Table 5. Characteristics of Patients Seen by Cardiologists, or Internists and Primary Care Physicians

\begin{tabular}{|c|c|c|c|}
\hline Patients $(n=1318)$ & 80.8 & 19.2 & \\
\hline Age, years & $72.8 \pm 49.3$ & $77.6 \pm 8.8$ & $<.001$ \\
\hline Women & 41.1 & 48.4 & .034 \\
\hline \multicolumn{4}{|l|}{ Comorbidities and CVRF } \\
\hline History of hypertension & 80.7 & 82.54 & .497 \\
\hline Diabetes mellitus & 27.7 & 36.1 & .008 \\
\hline Current smoker & 4.5 & 4.8 & .976 \\
\hline COPD/OSA & 16.5 & 18.2 & .506 \\
\hline Kidney disease & 17.9 & 23.8 & .032 \\
\hline Dialysis & 0.6 & 0.4 & .633 \\
\hline Liver disorder & 1.0 & 0.7 & .731 \\
\hline Thyroid dysfunction & 13.7 & 10.71 & .207 \\
\hline Alcohol or drug use & 3.28 & 6.75 & .011 \\
\hline Modified Charlson comorbidity index & $1.1 \pm 1.2$ & $1.3 \pm 1.2$ & .027 \\
\hline \multicolumn{4}{|l|}{ Heart history } \\
\hline Previous heart disease & 48.8 & 42.8 & .085 \\
\hline Heart failure & 29.2 & 32.1 & .370 \\
\hline Previous coronary disease & 19.3 & 15.4 & .158 \\
\hline Previous acute coronary syndrome & 14.9 & 13.1 & .461 \\
\hline Previous coronary revascularization & 11.4 & 8.7 & .214 \\
\hline Dilated cardiomyopathy & 13.7 & 5.9 & .001 \\
\hline Hypertrophic cardiomyopathy & 3.38 & 0 & .003 \\
\hline Rate control strategy & 55.9 & 80.8 & $<.001$ \\
\hline Antiarrhythmics (Ic or III) & 27.4 & 13.1 & $<.001$ \\
\hline Flecainide/propafenone & 10.4 & 4.0 & $<.001$ \\
\hline Amiodarone/dronedarone/sotalol & 16.7 & 9.0 & $<.001$ \\
\hline Rate-slowing drugs & 81.4 & 89.2 & $<.001$ \\
\hline Beta-blockers & 69.3 & 21.4 & $<.001$ \\
\hline Digoxin & 9.4 & 62.3 & $<.001$ \\
\hline Calcium channel antagonists & 10.3 & 12.3 & .363 \\
\hline
\end{tabular}

COPD, chronic obstructive pulmonary disease; HT, hypertension; I, internist; OSA, obstructive sleep apnea; PCP, primary care physician.

Data are expressed as a percentage or mean \pm standard deviation unless otherwise indicated. 


\section{Discussion}

The aim of NVAF management is 2-fold: to reduce patients' symptoms and prevent the serious complications of this condition. These 2 goals should be achieved simultaneously. The prevention of AVrelated complications is based on antithrombotic treatment, ventricular heart rate control and appropriate treatment of concomitant heart diseases. These measures alone may be sufficient to control symptoms, but symptomatic relief may also require additional rhythm control treatment by means of electrical or pharmacological cardioversion, or ablation. This cross-sectional analysis of NVAF data from the FANTASIIA Registry describes the characteristics of NVAF management in terms of treatment and antiarrhythmic management (choice of rhythm or rate control strategy, and use of pharmacological and nonpharmacological antiarrhythmic treatment). In our series, $28 \%$ of patients had paroxysmal NVAF and $50 \%$ had permanent NVAF, which was the most common type. These figures are similar to those described in other recent studies. ${ }^{1,8,9}$ and 10 The rate control strategy was used more than the rhythm control strategy, in $60 \%$ and $39 \%$ of patients, respectively. The preference for rate control was also observed in all analyzed subgroups, as shown in Table 2, although the lower use of rhythm control was more significant in older patients and those with comorbidities such as diabetes mellitus, chronic obstructive pulmonary disease, and renal impairment, and in patients with HF and reduced LVEF $(<$ $45 \%$ ) (Table 4). Rhythm control was also used less in patients seen by internists or primary care physicians $(19.2 \%$ vs $44 \%$ of patients seen by cardiologists; $P<.001)$. This lower preference for the rhythm control strategy may be explained by the results of studies showing nonsuperiority of rhythm over rate control. ${ }^{11,12,13,14 \text { and } 15}$

For example, the AFFIRM study ${ }^{11}$ did not observe superiority of either strategy with regard to reduced mortality or stroke. The 2 strategies were also found to be similar in the RACE study ${ }^{12}$ in terms of cardiovascular mortality among patients with AF and HF. This finding was repeated in the AF-CHF study, ${ }^{13}$ with cardiovascular mortality among patients with AF and LVEF $<35 \%$. The AFFIRM, ${ }^{11}$ RACE $^{12}$ PIAF, $^{14}$ and STAF $^{15}$ studies all found similar benefits from using rhythm vs rate control strategies in terms of quality of life. A more recent study, ${ }^{16}$ which enrolled more than 5000 unselected, community-based patients patients, has also confirmed the findings of the earlier studies. As Anguita et al have already observed, ${ }^{17}$ it appears contradictory that clinical practice guidelines continue to recommend rhythm control over rate control in their indications, without clear evidence in this respect. ${ }^{1}{ }^{2}$ Our study, however, found that in clinical practice, Spanish physicians show a preference for the rate control strategy. This preference is reasonable, considering the high mean age of the study population. The rate control strategy was used significantly more by noncardiologists than cardiologists (Table 5). However, these findings may be biased by the characteristics of the FANTASIIA population (advanced age, high prevalence of comorbidities and heart disease, low incidence of new-onset AF, chronic anticoagulant use, etc). The rhythm control strategy might have been more frequently chosen if the patient population were younger, with fewer comorbidities and no chronic anticoagulant use, as found in recent studies. ${ }^{8,9}$ and 10

Antiarrhythmic agents (Ic and III) were an uncommon choice in our study, accounting for just a quarter of the overall sample, possibly reflecting the low percentage of patients with the rhythm control strategy (Table 3). Of the antiarrhythmic agents used, amiodarone was the most common $(12.6 \%$ of patients), followed by flecainide $(8.9 \%)$, dronedarone $(2.3 \%)$, sotalol $(0.5 \%)$, and propafenone $(0.4 \%)$. This preference for amiodarone matches clinical practice guideline recommendations, ${ }^{1}$ and 2 which clearly state that amiodarone is the most effective and safest antiarrhythmic agent for maintaining sinus rhythm in patients who absolutely require this treatment, and particularly in those with severe structural heart disease and/or advanced or unstable HF. ${ }^{1 \text { and } 17}$ Other authors ${ }^{18 \text { and } 19}$ draw on their clinical experience to conclude that, although noncardiac side effects of amiodarone are greater than those of other antiarrhythmic agents, at the dosage used in AF and with close monitoring, these side effects can be reduced to a minimum or resolved in most patients simply by discontinuing the drug. The low percentage of dronedarone use in our setting appears to be reasonable in view of the current recommendations of the European Medicines Agency ${ }^{20}$ and results of the ANDROMEDA ${ }^{21}$ and PALLAS $^{22}$ studies. Also, in the only study comparing 2 antiarrhythmics, dronedarone was inferior to amiodarone in preventing AF recurrence $(63.5 \%$ vs $42 \%){ }^{23}$ In our study, class Ic antiarrhythmics were not very common, and they were hardly used at all in patients with reduced LVEF, as recommended in clinical practice guidelines. ${ }^{1 \text { and } 2}$ No patients received a combination of antiarrhythmics. Some patients, however, received a combination of antiarrhythmic and rate-slowing drugs, and beta-blockers and digoxin, in particular, in the rhythm control group (15.4\% of the total of this subgroup) (Table 3 ).

The most commonly used drugs for heart rate control in our study were beta-blockers (in $60.2 \%$ of the patients), digoxin $(19.5 \%)$, and calcium channel antagonists $(10.7 \%)$. This coincides with clinical practice guidelines that indicate preferential use of beta-blockers with a class I strength of recommendation and B level of evidence. ${ }^{1 \text { and } 2}$ Cardiologists used beta-blockers more than other rate-slowing drugs, while internists and primary care physicians used digoxin more. The use of beta-blockers and digoxin was 
similar in reduced and preserved LVEF (Table 4). These data match those observed in other recent studies in Europe. 8 and 9

In our study, cardioversion had previously been performed in $41.9 \%$ of the patients (electrical cardioversion in $19 \%$, pharmacological cardioversion in 22.9\%). Ablation in AF had been performed in only $3.4 \%$ of the patients, with the highest percentage in paroxysmal AF. The ablation figure may seem low, but the guidelines recommend precaution with this approach, ${ }^{1 \text { and } 2}$ and recent European registries in the general population with $\mathrm{AF}$ show similar figures of about $5 \%$ to $7 \% .^{8,9}$ and 10

\section{Study Limitations}

This study is a preliminary analysis of the baseline data in the FANTASIIA Registry, which is still underway. We need to wait until registry closure, scheduled for 2016, to perform a more detailed and appropriate analysis of the management, strategies and antiarrhythmic agents used for NVAF in Spain, because these variables will change over time, according to the clinical course of each patient. Another limitation is that by design, this study analyses drug treatment at the time of the enrollment visit, and does not include drug history or changes.

\section{Conclusions}

Currently, anticoagulated patients with any type of NVAF in Spain are mostly elderly, and more are treated with a rate control strategy than a rhythm control strategy. Beta-blockers are prescribed most in the rate control drug group. These patients receive few antiarrhythmic agents (amiodarone being the most common), and a very low percentage undergo nonpharmacological treatments such as ablation.

\section{Funding}

The FANTASIIA Registry receives an unrestricted grant from Pfizer/Bristol-Myers-Squibb.

\section{Conflicts of interest}

None declared.

\section{References}

1. A.J. Camm, G.Y.H. Lip, R. de Caterina, I. Savelieva, D. Atar, S.H. Hohnloser, et al. 2012 focused update of the ESC Guidelines for the management of atrial fibrillation. An update of the 2010 ESC Guidelines for the management of atrial fibrillation developed with the special contribution of the European Heart Rhythm Association Authors/Task Force Members. Eur Heart J., 33 (2012), pp. 2719-2747.

2. C.T. January, L.S. Wann, J.S. Alpert, H. Calkins, J.C. Cleveland Jr., J.E. Cigarroa, et al. 2014 AHA/ACC/HRS Guideline for the Management of Patients With Atrial Fibrillation: A report of the American College of Cardiology/American Heart Association Task Force on Practice Guidelines and the Heart Rhythm Society. Circulation., 130 (2014), pp. 199-267.

3. J.J. Gómez-Doblas, J. Muñiz, J.J. Alonso Martin, G. Rodríguez-Roca, J.M. Lobos, P. Awanleh, on behalf of the OFRECE study researchers, et al. Prevalencia de fibrilación auricular en España. Resultados del estudio OFRECE. Rev Esp Cardiol., 67 (2014), pp. 259-269.

4. P.S. Miller, F.L. Andersson, L. Kalra. Are cost benefits of anticoagulation for stroke prevention in atrial fibrillation underestimated?. Stroke., 36 (2005), pp. 360-366.

5. T.J. Wang, M.G. Larson, D. Levy, R.S. Vasan, E.P. Leip, P.A. Wolf, et al. Temporal relations of atrial fibrillation and congestive heart failure and their joint influence on mortality: the Framingham Heart Study. Circulation., 107 (2003), pp. 2920-2925.

6. A.D. Krahn, J. Manfreda, R.B. Tate, F.A. Mathewson, T.E. Cuddy. The natural history of atrial fibrillation: incidence, risk factors, and prognosis in the Manitoba Follow-Up Study. Am J Med., 98 (1995), pp. 476-484.

7. S. Stewart, C.L. Hart, D.J. Hole, J.J. McMurray. A population-based study of the long-term risks associated with atrial fibrillation: 20-year follow-up of the Renfrew/Paisley study. Am J Med., 113 (2002), pp. 359-364.

8. P. Kirchchof, B. Ammentorp, H. Darius, R. De Caterina, J.Y. Le Heuzey, R.J. Schilling, et al. Management of atrial fibrillation in seven European countries after the publication of the 2010 ESC Guidelines on atrial fibrillation: primary results of the PREFER in AF. Europace., 16 (2014), pp. 6-14

9. G.Y.H. Lip, C. Laroche, G.A. Dan, M. Santini, Z. Kalarus, L.H. Rasmussen, et al. A prospective survey in European Society of Cardiology member countries of atrial fibrillation management: baseline results of EORPAF Pilot General Registry. Europace., 16 (2014), pp. 308-319. 
10. G.Y.H. Lip, C. Laroche, P.M. Ioachim, L.H. Rasmussen, L. Vitali-Serdoz, L. Petrescu, et al. Prognosis and treatment of atrial fibrillation patients by European cardiologists: one year follow-up of the EORP-AF Pilot registry. Eur Heart J., 35 (2014), pp. 3365-3376.

View Record in Scopus

11. D.G. Wyse, A.L. Waldo, J.P. Demarco, M.J. Domanski, Y. Rosenberg, E.B. Schron, AFFIRM Investigators, et al. A comparison of rate control and rhythm control in patients with atrial fibrillation. N Engl J Med., 347 (2002), pp. $1825-1833$.

12. I.C. Van Gelder, V.E. Hagens, H.A. Bosker, H. Kingma, O. Kamp, T. Kingma, et al. A comparison of rate control and rhythm control in patients with recurrent persistent atrial fibrillation. N Engl J Med., 347 (2002), pp. 18341840.

13. D. Roy, M. Talajic, S. Nattel, D.G. Wyse, P. Dorian, K.L. Lee, et al. Rhythm control versus rate control for atrial fibrillation and heart failure. N Engl J Med., 358 (2008), pp. 2667-2677.

14. S.H. Hohnloser, K.H. Kuck, J. Lilienthal. Rhythm or rate control in atrial fibrillation. Pharmacological intervention in atrial fibrillation (PIAF): a randomised trial. Lancet., 356 (2000), pp. 1789-1794.

15. J. Carlsson, S. Miketic, J. Windeler, A. Cuneo, S. Haun, S. Micus, et al. Randomized trial of rate-control in persistent atrial fibrillation. J Am Coll Cardiol., 41 (2003), pp. 1690-1696.

16. A.J. Camm, G. Breithardt, H. Crijns, P. Dorian, P. Kowey, J.Y. Le Heuzey, et al. Real life observations of clinical outcomes with rhythm- and rate-control therapies for atrial fibrillation RECORDAF (Registry on Cardiac Rhythm Disorders Assessing the Control of Atrial Fibrillation). J Am Coll Cardiol., 58 (2011), pp. 493-501.

17. M. Anguita, F. Worner, P. Domenech, F. Marín, J. Ortigosa, Pérez-Villacastín, et al. Nuevas evidencias, nuevas controversias: análisis crítico de la guía de práctica clínica sobre fibrilación auricular 2010 de la Sociedad Europea de Cardiología. Rev Esp Cardiol., 65 (2012), pp. 7-13.

18. L. Benito, J. Hoyo, A. Montroig, B. Fornés, G. Fluxaá, D. Martí, et al. Estudio sobre los efectos adversos de los fármacos antiarrítmicos en pacientes con fibrilación auricular atendidos en un Centro de Atención Primaria. Med Clin (Barc)., 137 (2011), pp. 241-246.

19. L. Van Erven, M.J. Schalij. Amiodarone: an effective antiarrhythmic drug with unusual side effects. Heart., 96 (2010), pp. 1593-1600.

20. Dronedarona (MultaqW): conclusiones de la revaluación de su relación beneficio riesgo [nota informativa 16/2011]. Available at: http://www.aemps.gob.es/informa/notasInformativas/medicamentosUsoHumano/seguridad/2011.

21. L. Kober, Torp-Pedersen Ch, J.J. McMurray, O. Gotzsche, S. Lévy, H. Crijns, et al. Increased mortality after dronedarone therapy for severe heart failure. N Engl J Med., 358 (2008), pp. 2678-2687.

22. S.J. Connolly, A.J. Camm, J.L. Halperin, C. Joyner, M. Alings, J. Amerena, PALLAS Investigators, et al. Dronedarone in high-risk permanent atrial fibrillation. N Engl J Med., 365 (2011), pp. 2268-2276.

23. J. Le Heuzey, G.M. De Ferrari, D. Radzik, M. Santini, J. Zhu, J.M. Davy. A short-term, ramdomized, doubleblind, parallel group study to evaluate the efficacy and safety of dronedorone versus amiodarone in patients with persistent atrial fibrillation: the DIONYSOS study. J Cardiovasc Electrophysiol., 21 (2010), pp. 597-605. 